Jaime Aparecido Cury ${ }^{(a)}$ Livia Maria Andaló Tenuta ${ }^{(b)}$

(a) Professor; (b) Assistant Professor of Biochemistry and Cariology, Piracicaba Dental School, State University of Campinas (UNICAMP), Piracicaba, SP, Brazil.

\section{Enamel remineralization: controlling the caries disease or treating early caries lesions?§}

\begin{abstract}
The emphasis currently given to new technologies for enamel remineralization suggests that the changes in the understanding of the dental caries disease, which occurred in the last century, were either not yet adopted or were forgotten. Just like in the past, when the disease was "treated" by restoring cavities, there is presently a misunderstanding on the concept of incipient lesion remineralization. The aim of this paper was to review some concepts about caries, the natural phenomenon of enamel remineralization and the effect of fluoride $(\mathrm{F})$ on it, and also to discuss the clinical relevance of remineralizing products recently launched in the marketplace aiming to "treat early caries lesions".
\end{abstract}

Descriptors: Dental caries; Dental enamel; Tooth remineralization; Fluorides.
§Paper presented at the "Oral Health Self-Care Products: Realities and Myths" international symposium, sponsored by the Brazilian Association for Oral Health Promotion (ABOPREV), September 25-27, 2008, São Paulo, SP, Brazil.

Corresponding author:

Jaime Aparecido Cury

Faculdade de Odontologia de Piracicaba

Caixa Postal 52

CEP: 13414-903

Piracicaba - SP - Brazil

E-mail: jcury@fop.unicamp.br

Received for publication on May 02, 2009

Accepted for publication on May 12, 2009 


\section{Dental caries: the disease and its signals}

For many years in the past, the dental profession had difficulty to distinguish dental caries as a disease from its signals: the caries lesions. Therefore when a cavity was filled, not only the professional believed that he was performing the best treatment, but the patient also believed that he/she was being treated for the disease.

A cavity, however, is only the terminal stage of a progressive mineral loss provoked in enamel by caries as a silent disease, dependent on the presence of biofilm and sugar exposure. Biofilm (plaque) and sugar are respectively necessary and determinant factors for the manifestation of the disease, ${ }^{1}$ i.e., bacteria need to accumulate on dental surfaces and be frequently exposed to dietary sugars for dental caries to develop. The disease progresses silently until the changes provoked in enamel by biofilm-sugar are clinically visible, i.e., a white spot lesion is present. If the disease is not controlled, dental destruction will not be prevented (Graph 1). ${ }^{2}$

When white spots were recognized as caries lesions that could develop into cavities, a clinical discussion on strategies to repair or revert the changes provoked by the disease in enamel through a noninvasive treatment started in Dentistry. However, if the disease signs are the only factors taken into consideration, the strategies used to treat patients with white spot lesions or early signs of the disease may repeat the same mistakes made in the past when filling was considered the solution for caries. ${ }^{3,4}$

Furthermore, there is clear evidence showing that the main effect found when a white spot lesion becomes clinically less evident (and does not progress to a cavity) is the result of mechanical abrasion of the enamel surface, and not only of repair ("remineralization") of the mineral loss suffered by enamel. ${ }^{2}$ Understanding that the "treatment of a white spot" was not only the result of true reprecipitation of minerals (remineralization) was very important because it emphasized the relevance of plaque control not only to arrest the lesion but also to restore the physiological equilibrium between tooth minerals and oral fluids (and allow natural remineralization from saliva) and, as a result, control the disease. ${ }^{5}$
The consequence of disease control would be seen clinically by a change in the appearance of white spots, from chalky and rough (active) to bright and smooth (inactive). Eventually, the white spot could even disappear.

Although arrestment of caries lesions is not merely a "remineralization" of white spots, this should not be used to cast doubt on the natural phenomenon of enamel remineralization which occurs in the oral cavity, and its enhancement by fluoride. ${ }^{6}$

\section{Enamel remineralization}

At physiological conditions, the oral fluids (saliva, biofilm fluid) have calcium $(\mathrm{Ca})$ and phosphate $\left(\mathrm{P}_{\mathrm{i}}\right)$ in supersaturated concentrations with respect to the mineral composition of enamel and, as a result, these ions are continually deposited on the enamel surface or are redeposited in enamel areas where they were lost. This can be considered a natural defense phenomenon promoted by saliva to preserve the mineral structure of enamel in the mouth. ${ }^{6}$ Therefore, remineralization would be best defined as the redeposition of minerals lost by enamel, and this term has been used as a synonymous of enamel repair or rehardening.

Mineral loss (demineralization) or gain (remineralization) by enamel is a dynamic physicochemical process occurring when oral bacteria form a biofilm

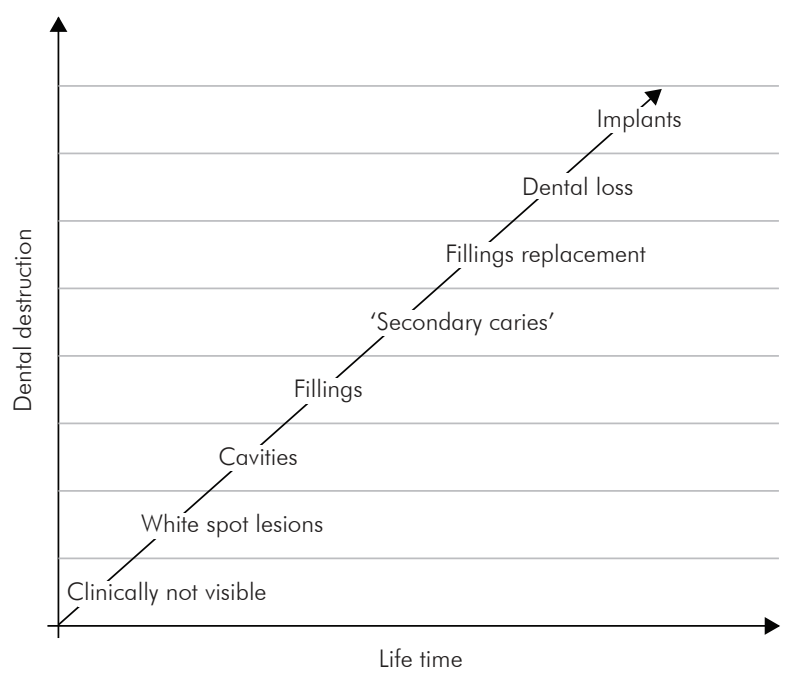

Graph 1 - Progressive enamel mineral loss and dental destruction under biofilm accumulation and frequent sugar exposure in the absence of fluoride use. ${ }^{2}$ 
on the enamel surface and this biofilm is exposed to fermentable dietary carbohydrates, sucrose being the most cariogenic of them. ${ }^{7}$ Thus, every time sugar penetrates into a cariogenic biofilm and is converted to acids by bacterial metabolism, the biofilm fluid becomes undersaturated with respect to the enamel mineral, and demineralization occurs. ${ }^{8}$ A critically low $\mathrm{pH}$ for tooth dissolution is maintained for a certain time, but it returns to physiological values when exposure to sugar ceases. Therefore, when the $\mathrm{pH}$ is raised and the supersaturating conditions are restored, a certain amount of the mineral lost can be recovered by enamel. This process has been named remineralization. Redeposition of the mineral lost by enamel can occur by $\mathrm{Ca}$ and $\mathrm{P}_{\mathrm{i}}$ found in the biofilm fluid or by direct action of salivary $\mathrm{Ca}$ and $\mathrm{P}_{\mathrm{i}}$ soon after the biofilm is removed by toothbrushing. The amount of $\mathrm{Ca}$ and $\mathrm{P}_{\mathrm{i}}$ gained, however, is lower than that lost, and the net result is a small mineral loss.

If the factors responsible for the disease - biofilm accumulation and frequent sugar exposure - are not controlled, enamel mineral loss cannot be stopped (Graph 1). ${ }^{2}$ Repeated events of mineral dissolution will eventually surpass the capacity of oral fluids to repair mineral loss, and the disease will show its first clinical signs: white spot lesions. Differences in the progression rate of caries lesions in different individuals or populations can also be the result of other factors which modulate the caries process, since caries is a "multifactorial" or "complex dis-

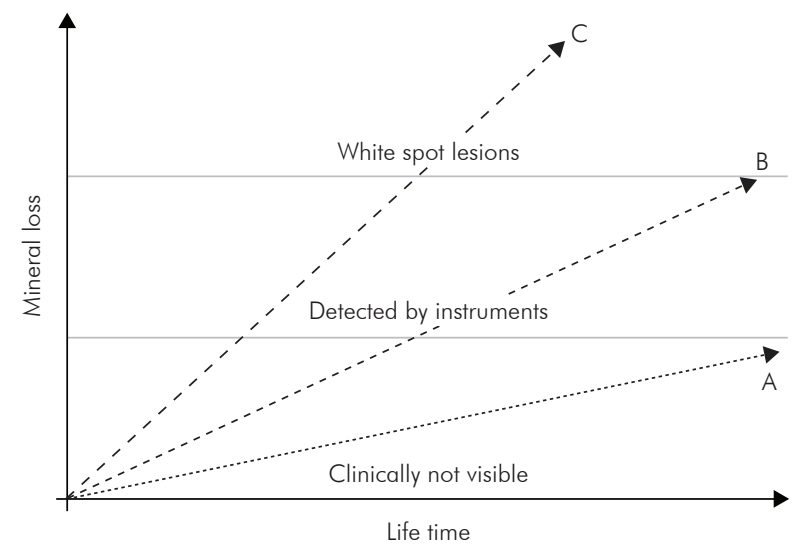

Graph 2 - Enamel mineral loss progression during the lifetime of different individuals or populations $(A=$ slow; $B=$ moderate; $\mathrm{C}=$ fast $).{ }^{4}$ ease", and the risk of developing new lesions is never zero. ${ }^{5}$ In some individuals, lesions will progress slowly, and the disease might not be clinically detected throughout their lifetime. In others, they will progress rapidly, and the manifestation of the disease will become clinically evident (white spots) before cavitation (Graph 2). Additionally, the progression from non-cavitated to cavitated lesions could be arrested, and the strategies used should consider if the lesions are "active or not". 9 This classification is aimed to correctly diagnose caries as a disease, as the basis for treatment decision. ${ }^{9}$

\section{Fluoride effect on the dynamics of the caries process}

Nowadays there is a consensus that the predominant effect of fluoride (F) is not systemic, by preeruptively changing the enamel structure, but mainly locally, by interfering with the caries process. ${ }^{10}$ Hence, $\mathrm{F}$ must be present in the right place (biofilm fluid or saliva), and at the right time (when biofilm is exposed to sugar or right after biofilm removal) to interfere with de- and remineralization events. For this effect, even below ppm values of $\mathrm{F}$ available are effective.

Thus, as described previously, enamel is dissolved by the lowering of $\mathrm{pH}$ in dental plaque due to acid production every time sugar is ingested (Figure 1). However, if $\mathrm{F}$ is present in the biofilm fluid, and the $\mathrm{pH}$ is not lower than 4.5 , hydroxyapatite (HA) is dissolved at the same time that fluorapatite (FA) is formed. ${ }^{6}$ The net result is a decrease in enamel dissolution, since a certain amount of $\mathrm{Ca}$ and $\mathrm{P}_{\mathrm{i}}$, which was lost as HA, is recovered by enamel as FA. This mineral gain as FA during the $\mathrm{pH}$ drop (Figure 1) has not been considered as remineralization but rather as a decrease in demineralization because the mineral redeposited is different from that lost. Furthermore, FA is deposited on the surface layer of enamel while HA is dissolved from the subsurface.

This indirect effect of $\mathrm{F}$ reducing enamel demineralization when the $\mathrm{pH}$ drops is complemented by its natural effect on remineralization when the $\mathrm{pH}$ rises (Figure 2) enhancing the redeposition of $\mathrm{Ca}$ and $\mathrm{P}_{\mathrm{i}}$ present in the biofilm fluid on demineralized enamel. If the demineralized enamel is cleaned by 
Figure 1 - Enamel demineralization in the presence of $F$ in dental biofilm. Sugars (sucrose, glucose, fructose) are converted to acids in the biofilm. When the $\mathrm{pH}$ decreases to below 5.5, undersaturation with respect to hydroxyapatite $(\mathrm{HA})$ is reached in the biofilm fluid, resulting in mineral dissolution. However, if the $\mathrm{pH}$ is higher than 4.5 and $\mathrm{F}$ is present, the biofilm fluid is supersaturated with respect to fluorapatite (FA) and there is reprecipitation of minerals in the enamel. As a consequence, the net demineralization is reduced. ${ }^{10}$

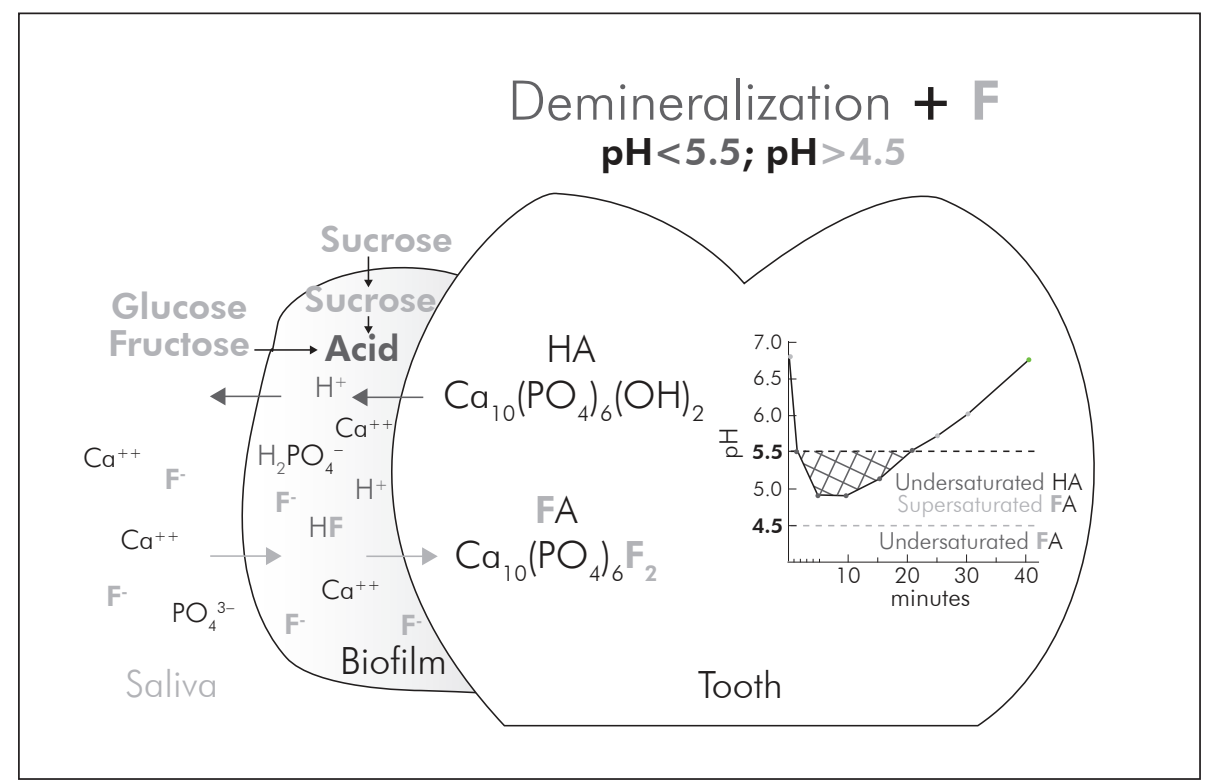

Figure 2 - Enamel remineralization in the presence of $F$ in dental biofilm. After the exposure to sugars has ceased, acids in the biofilm are cleared by saliva and converted to salts. As a result, the $\mathrm{pH}$ increases and, at 5.5 or higher, the biofilm fluid is supersaturated with respect to $\mathrm{HA}$ and FA. Thus, $\mathrm{Ca}$ and $\mathrm{P}_{\mathrm{i}}$ lost by enamel can be more efficiently recovered if $\mathrm{F}$ is still present in the biofilm. ${ }^{10}$

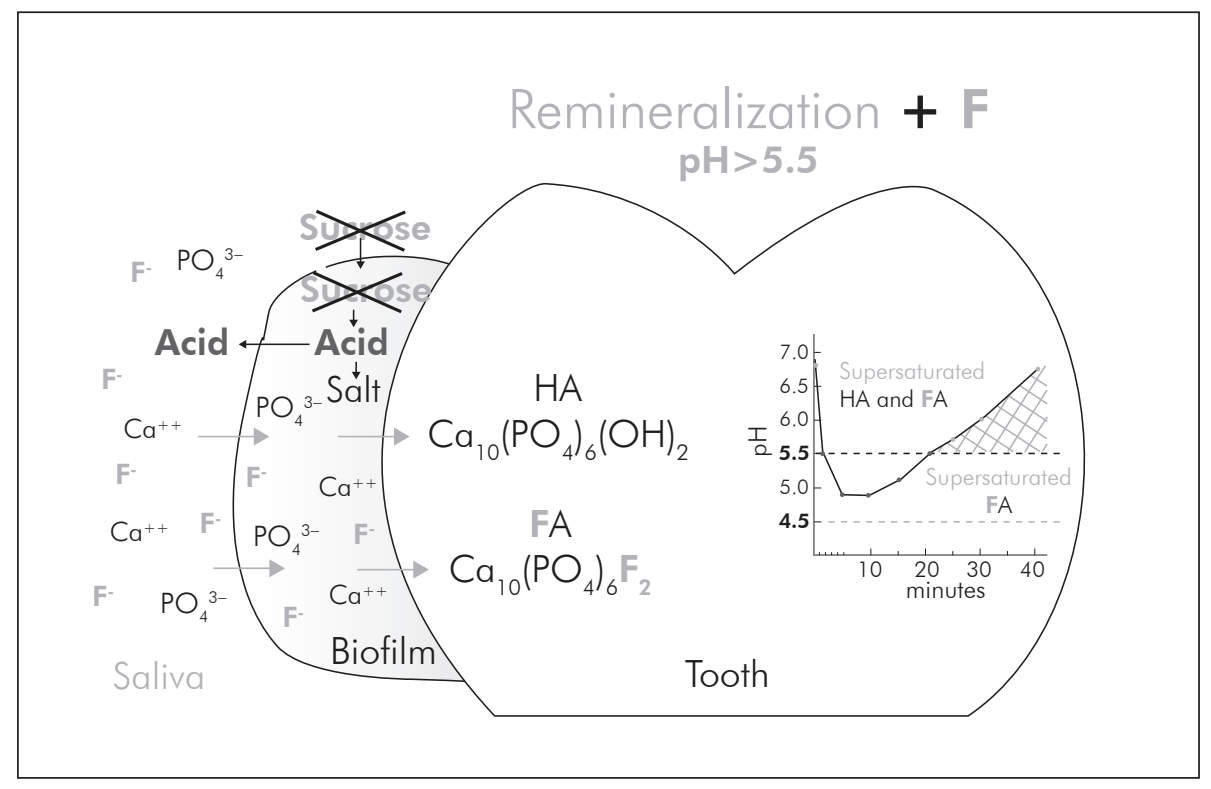

brushing, saliva is able to remineralize it,${ }^{11}$ but in the presence of $\mathrm{F}$ this effect is enhanced. ${ }^{12}$ As a result, small amounts of $\mathrm{Ca}$ and $\mathrm{P}_{\mathrm{i}}$ lost by enamel during the $\mathrm{pH}$ drop can be more efficiently recovered if $\mathrm{F}$ is still present in the oral environment (biofilm fluid or saliva) after the cariogenic challenge. This effect should be considered natural, not induced, because it occurs irrespective of patient compliance or dentist intervention if, for example, a F-dentifrice is being used and $\mathrm{F}$ is made available to the oral cavity.

By acting on the dynamics of the caries process, ${ }^{10}$
$\mathrm{F}$ is very effective in slowing down (retarding) the progress of caries lesions. However, since it does not have a direct effect on the etiological factors responsible for the disease (biofilm and sugar), it will not avoid it, and invariably the disease will leave scars on teeth, clinically visible or not (Graph 3).

Nonetheless, the relative contribution of $\mathrm{F}$ - reducing demineralization or enhancing remineralization - to the final effect on caries is not known because it is impossible to isolate these effects considering the dynamics of the process. ${ }^{13}$ Indeed, some 


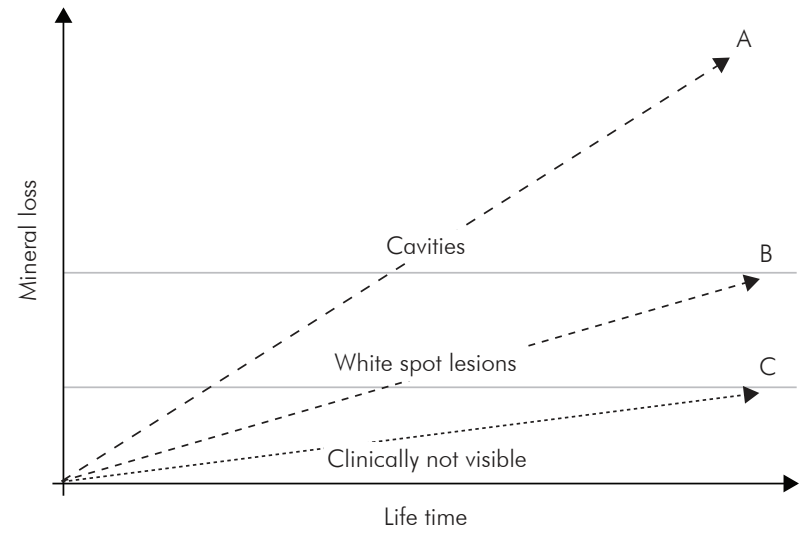

Graph 3 - Slowing down of the progression of enamel caries lesions by fluoride acting in the dynamics of the caries process. No $F(A)$; F effect under moderate (B) or low caries activity (C).

authors believe that the most important $\mathrm{F}$ effect is a reduction of enamel demineralization ${ }^{14}$ while others consider that $\mathrm{F}$ speeds up the remineralization process, and this is the main mechanism of caries control. ${ }^{15}$

The effect of $F$ on the reduction of enamel demineralization or enhancement of remineralization can be clearly shown in vitro using $\mathrm{pH}$-cycling models which simulate clinical situations of predominance of demineralization (De $>\mathrm{Re}$ ) or of remineralization $(\mathrm{Re}>\mathrm{De}) .{ }^{16}$ Graph 4 shows the effect of fluoride on sound enamel when De $>\operatorname{Re}$ (patient under caries activity). The efficacy of $\mathrm{F}$ in decreasing enamel surface hardness loss and in reducing lesion depth are shown, as is the gain of $\mathrm{F}$ by enamel, which is a consequence of mineral change if $\mathrm{F}$ is present during the caries process.

\section{Fluoride effect on caries lesions}

Since $\mathrm{F}$ enhances enamel remineralization, its clinical use to repair early caries lesions was advocated ("fluoride therapy"). However, the effect of $F$ in the dynamics of the caries process and its success in controlling caries should not be confused with its arrestment or reversal effect on caries lesions. Furthermore, it should be emphasized that shallow demineralized enamel areas remineralize faster than deep ones.

Arrestment of white spot caries lesions and the changes observed in a demineralized enamel sur- face and subsurface were well documented 25 years ago. ${ }^{17}$ Change in enamel lesions from a whitish to a shiny appearance was explained in terms of wear and polishing of the dull, partly dissolved surface of the active lesions, rather than redeposition of mineral lost. ${ }^{2}$ However, the porosity of the deeper parts of the lesions was reduced, suggesting a partial remineralization of the lesion body.

Therefore the presence of a surface layer does not prevent subtle alterations at the crystals level inside the caries lesions after removing the biofilm accumulated on the enamel surface. ${ }^{2}$ Re-establishing the physiological conditions between enamel and oral fluids will lead to the redeposition of minerals in the demineralized areas. However, while subsurface lesions remineralize in vitro within weeks, years are required for a complete remineralization in vivo. ${ }^{18}$

The effect of $\mathrm{F}$ on enamel remineralization is easily shown in vitro. ${ }^{16}$ Graph 5 shows the effect of $\mathrm{F}$ on enamel with a "caries lesion" simulating a clinical situation under low caries challenge (Re $>$ De). The enamel surface was rehardened, the lesion depth was reduced and there was an increase in $\mathrm{F}$ concentration in the remineralized enamel. However, the lesion was not totally repaired.

Therefore, if the biofilm accumulated on the enamel surface presenting non-cavitated active caries lesions is controlled by brushing with a F-containing dentifrice, it is not surprising that the lesions can not only be arrested, ${ }^{19-21}$ but also partially repaired (Graph 6). Even cavitated lesions can be arrested. ${ }^{2}$

In summary, the effect of $\mathrm{F}$ in enhancing enamel remineralization is well known from several in vitro and in situ studies, ${ }^{22}$ but considering the best knowledge about dental caries, any "remineralizing therapy" should follow two fundamental principles:

1. Dental biofilm, the necessary factor responsible for caries lesions, should be controlled by toothbrushing.

2. Fluoride should be used either to arrest existing lesions or to reduce the progression of new ones.

It should be emphasized that the source of minerals to rebuild demineralized enamel are salivary $\mathrm{Ca}$ and $\mathrm{P}_{\mathrm{i}}$ since saliva is supersaturated with respect to tooth mineral, favoring mineral precipitation. 


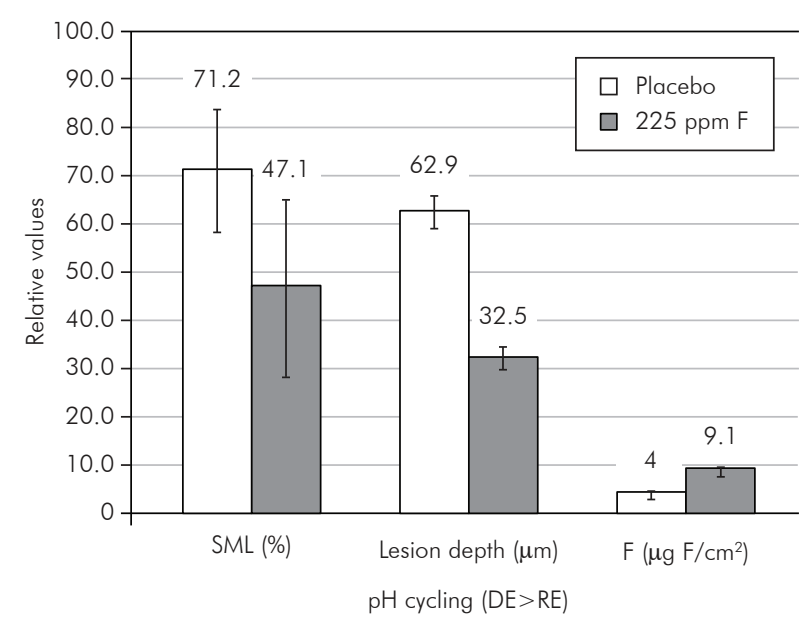

Graph 4 - Enamel surface microhardness loss (SML, \%), lesion depth $(\mu \mathrm{m})$ and total fluoride in enamel $\left(\mu \mathrm{gF} / \mathrm{cm}^{2}\right)$ after a demineralizing ( $\mathrm{De}>\mathrm{Re}$ ) $\mathrm{pH}$-cycling regimen, according to the treatments (mean $\pm S D ; n=10$ ). The differences were statistically significant $(p<0.05) . .^{16}$

Therefore, the normal endogenous concentrations of $\mathrm{Ca}$ and $\mathrm{P}_{\mathrm{i}}$ found in saliva are high enough to induce remineralization, but the latter can be significantly enhanced by exogenous F, supplied by different ways of oral delivery. ${ }^{23}$

\section{News technologies for enamel remineralization}

Enamel remineralization has been studied for about 100 years, and it has been suggested that "the non-invasive treatment of early caries lesions by remineralization has the potential to be the major advance in the clinical management of the disease". ${ }^{24}$

This subject was recently reviewed, ${ }^{24}$ as well as the effect of the three remineralizing products launched in the marketplace after 2000, all based on calcium phosphate remineralization systems. One technology involves casein phosphopeptide stabilized amorphous calcium phosphate (CPP-ACP; Recaldent $\left.{ }^{\mathrm{TM}}\right)$, the second is an unstabilized amorphous calcium phosphate (ACP, Enamelon ${ }^{\mathrm{TM}}$ ) and the third is a bioactive glass containing calcium sodium phosphosilicate $\left(\right.$ Nova Min $\left.{ }^{\mathrm{TM}}\right)$. Since all systems rely on calcium and phosphate compounds, their effect is mainly based on an enhancement of the natural capacity of saliva to remineralize mineral loss.

The clinically-based evidence to support these

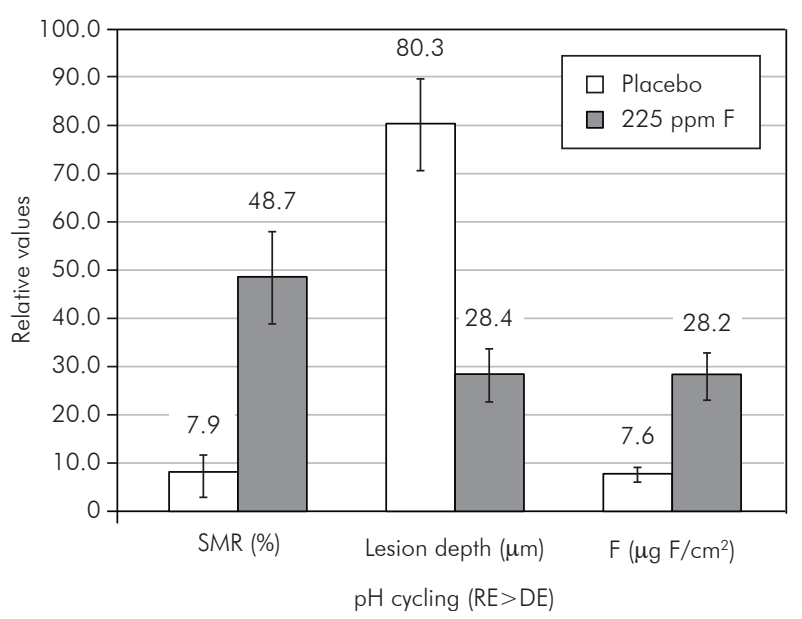

Graph 5 - Enamel surface microhardness recovery (SMR, $\%)$, lesion depth $(\mu \mathrm{m})$ and total fluoride in enamel $\left(\mu \mathrm{gF} / \mathrm{cm}^{2}\right)$ after a remineralizing $(\mathrm{Re}>\mathrm{De}) \mathrm{pH}$-cycling regimen, according to the treatments (mean $\pm S D ; n=10$ ). The differences were statistically significant $(p<0.05) .{ }^{16}$

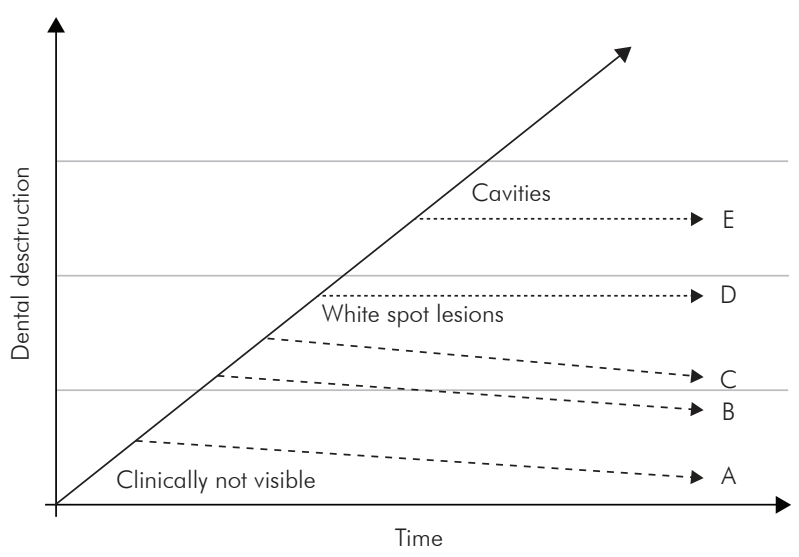

Graph 6 - Effect of fluoride and biofilm control on enamel caries lesions arrestment $(D, E)$ and repair $(A, B, C)$.

products is currently not abundant. A literature search of the PubMed database conducted in April, 2009 using the key words Recaldent or Enamelon or Novamin alone or combined with remineralization AND caries AND review resulted in the number of papers listed in Table 1.

Recaldent is the most studied system. The available reviews on it state either that it could significantly slow the progression of coronal caries and promote the regression of lesions, ${ }^{24}$ or that there is insufficient clinical trial evidence, in quantity and also quality, to make any recommendation on 
Table 1 - Number of publications in PubMed according to product name combined with selected key words.

\begin{tabular}{c|c|c|c}
\hline \multirow{2}{*}{ Key Words } & \multicolumn{3}{|c}{ Number of Papers $^{*}$} \\
\cline { 2 - 4 } & Recaldent $^{\mathrm{TM}}$ & Enamelon $^{\mathrm{TM}}$ & Novamin $^{\mathrm{TM}}$ \\
\hline Product Name (PN) & $58^{*}$ & $17^{* *}$ & $7^{* * *}$ \\
\hline $\mathrm{PN}$ and Remineralization (PN and Re) & 34 & 12 & 1 \\
\hline $\mathrm{PN}$ and Re and caries (PN and Re and C) & 18 & 9 & 1 \\
\hline PN and Re and C and review & 4 & 2 & 1 \\
\hline
\end{tabular}

$1^{\text {st }}$ publication in: ${ }^{*} 2001 ;{ }^{* *} 1998$ and ${ }^{* * *} 1952$ (anti-allergic drug).

the clinical use of this product. ${ }^{25}$ As for Enamelon, except for a descriptive publication made by the manufacturers of this commercial product, ${ }^{26}$ the only other review, published by Reynolds ${ }^{24}$ (2008), concluded that there is evidence that Enamelon has an anticariogenic effect on root caries. Except for the paper by Reynolds ${ }^{24}$ (2008), no other paper was found on Novamin ${ }^{\mathrm{TM}}$ AND remineralization in PubMed, but a great number of abstracts have been presented in the last IADR meetings (54 in 2008 and 24 in 2009).

As Reynolds ${ }^{24}$ (2008) concluded, “calcium phosphate-based remineralization technologies show promise as adjunctive treatments to fluoride therapy in the non-invasive management of early caries lesions", since they do not have general recommendation, but some people could benefit from them. Otherwise, they would not be a solution to the problem of controlling caries disease.

\section{Conclusions}

1. Inicipient caries lesions regress or clinically dis- appear due to mechanical removal of affected enamel and true reprecipitation of minerals (remineralization), both of which are dependent on the control of caries as a disease.

2. Remineralization occurs naturally by the action of saliva.

3. Fluoride slows down caries progression by interfering with the dynamics of the process, reducing enamel demineralization and enhancing its remineralization.

4. Remineralization is activated by fluoride.

5. Any strategy to reduce the progression of caries lesions should be based on the control of caries as a biofilm-dependent disease.

6. The repair of early caries lesions may be speeded up by an exogenous $\mathrm{Ca}$ and $\mathrm{P}_{\mathrm{i}}$ supply, but the clinical significance of the remineralization should be better evaluated.

7. The calcium phosphate-based remineralization technology could help some patients but it does not have general recommendation.

\section{References}

1. Fejerskov O, Thylstrup A. Different concepts of dental caries and their implications. In: Textbook of clinical cariology. $2^{\text {nd }}$ ed. Munksgaard, Copenhagen; 1994. chapter 9.

2. Fejerskov O, Nyvad B, Kidd E. A. M. Pathology of dental caries. In: Fejerskov O, Kidd E (ed). Dental caries - The disease and its clinical management. $2^{\text {nd }}$ ed. Oxford: Blackwell Munksgaard; 2008. chap. 3.

3. Ardu S, Castioni NV, Benbachir N, Krejci I. Minimally invasive treatment of white spot enamel lesions. Quintessence Int. 2007;38(8):633-6.

4. Diefenderfer KE, Stahl J. Caries remineralization therapy: implications for dental readiness. Mil Med. 2008;173(1 Suppl):48-50.

5. Fejerskov O. Changing paradigms in concepts on dental caries: consequences for oral health care. Caries Res. 2004;38(3):18291. Review.

6. ten Cate JM, Larsen MJ, Pearce EIF, Fejerskov O. Chemical interactions between the tooth and oral fluids. In: Fejerskov O, Kidd E (ed). Dental caries - The disease and its clinical management. $2^{\text {nd }}$ ed. Oxford: Blackwell Munksgaard; 2008. chap. 12.

7. Dawes C. What is the critical $\mathrm{pH}$ and why does a tooth dissolve in acid? J Can Dent Assoc. 2003;69:722-4.

8. Paes Leme AF, Dalcico R, Tabchoury CP, Del Bel Cury AA, Rosalen PL, Cury JA. In situ effect of frequent sucrose exposure on enamel demineralization and on plaque composi- 
tion after APF application and F dentifrice use. J Dent Res. 2004;83:71-5.

9. Nyvad B. Diagnosis versus detection of caries. Caries Res. 2004;38(3):192-8. Review.

10. Cury JA, Tenuta LM. How to maintain a cariostatic fluoride concentration in the oral environment. Adv Dent Res. 2008;20(1):13-6.

11. Edgar WM, Higham SM. Role of saliva in caries models. Adv Dent Res. 1995;9:235-8.

12. Dijkman A, Huizinga E, Ruben J, Arends J. Remineralization of human enamel in situ after 3 months: the effect of not brushing versus the effect of an F dentifrice and an F-free dentifrice. Caries Res. 1990;24:263-6.

13. Arends J, ten Bosh JJ. In vivo de- and remineralization of dental enamel. In: Leach SA. Factors relating to demineralization and remineralization of the teeth. Oxford: IRL Press Limited; 1985. p. 1-11.

14. ten Cate JM. Current concepts on the theories of the mechanism of action of fluoride. Acta Odontol Scand. 1999;57(6):325-9. Review.

15. Featherstone JD. Dental caries: a dynamic disease process. Aust Dent J. 2008;53(3):286-91.

16. Moi GP, Tenuta LM, Cury JA. Anticaries potential of a fluoride mouthrinse evaluated in vitro by validated protocols. Braz Dent J. 2008;19(2):91-6.

17. Holmen L, Thylstrup A, Artun J. Surface changes during the arrest of active enamel carious lesions in vivo. A scanning electron microscope study. Acta Odontol Scand. 1987;45(6):38390.
18. Arends J, Gelhard TBFM. In vivo remineralization of human enamel. In: Leach SA, Edgard WM. Demineralization and remineralization of the teeth. Oxford: IRL Press Limited; 1983. p. 1-16.

19. Machiulskiene V, Richards A, Nyvad B, Baelum V. Prospective study of the effect of post-brushing rinsing behaviour on dental caries. Caries Res. 2002;36(5):301-7.

20. Baelum V, Machiulskiene V, Nyvad B, Richards A, Vaeth M. Application of survival analysis to carious lesion transitions in intervention trials. Community Dent Oral Epidemiol. 2003;31(4):252-60.

21. Lima TJ, Ribeiro CCC, Tenuta LMA, Cury JA. Low-fluoride dentifrice and caries lesions control in children with different caries experience: a randomized clinical trial. Caries Res. 2008;42(1):46-50.

22. Featherstone JDB. Clinical aspects of de/remineralization of teeth. Adv Dent Res. 1995;49(3):175-340.

23. Ellwood R, Fejerskov O, Cury JA, Clarkson B. Fluoride in caries control. In: Fejerskov O, Kidd E (eds). Dental caries: The disease and its clinical management. $2^{\text {nd }}$ ed. Oxford: Blackwell Munksgaard; 2008. p. 287-323.

24. Reynolds EC. Calcium phosphate-based remineralization systems: scientific evidence? Aust Dent J. 2008;53(3):268-73. Review.

25. Azarpazhooh A, Limeback H. Clinical efficacy of casein derivatives: a systematic review of the literature. J Am Dent Assoc. 2008;139(7):915-24; quiz 994-5. Review.

26. Winston AE, Bhaskar SN. Caries prevention in the $21^{\text {st }}$ century. J Am Dent Assoc. 1998;129(11):1579-87. 